\title{
RESPONSABILIDAD SOCIAL UNIVERSITARIA: LA PERSPECTIVA DE LOS COLABORADORES EN UNA UNIVERSIDAD COMUNITARIA BRASILEÑA
}

\author{
University social responsibility: collaborators's perspective in a Brazilian \\ community university
}

\author{
Ricardo Antonio de Marco \\ e-mail: ricardo.antonio.demarco@gmail.com \\ Dirleia Fanfa Sarmento \\ e-mail: dirleia.sarmento@unilasalle.edu.br \\ Unilasalle Canoas. Brasil \\ María de Lourdes Pinto de Almeida \\ e-mail:malu04@gmail.com \\ Universidade do Oeste de Santa Catarina. Brasil
}

\section{RESUMEN}

El artículo analiza la percepción de las universidades comunitarias en la implementación de la Responsabilidad Social y visualiza el nivel de compromiso social de las actividades en la visión de dirigentes, coordinadores, profesores y técnicos. Se ha realizado investigación exploratoria y descriptiva, de carácter cuantitativo y cualitativo, bajo los criterios inclusión social, desarrollo económico y social, defensa del medio ambiente, del patrimonio y memoria cultural, de la producción artística y deportiva, y salud y organización administrativa. Los resultados señalan que la Responsabilidad Social Universitaria implica organización, misión institucional y documentos como guía de acciones, proyectos y prácticas de formación ciudadana.

PALABRAS CLAVE: responsabilidad social universitaria; colaboradores universitarios; universidades comunitarias brasileñas; organización administrativa de la universidad; misión institucional.

\begin{abstract}
The article analyzes the perception of community universities in the implementation of Social Responsibility, aiming at visualizing the level of social commitment of the activities from the perspective of managers, coordinators, teachers and administrative technicians. We carried out exploratory and descriptive research, of quantitative and qualitative character, under the criteria of social inclusion, economic and social development, environmental protection, patrimony and cultural memory, artistic and sportive production, and health and administrative organization. The results show that the University Social Responsibility goes through organization, mission and official documents as guide the actions, projects and activities for citizen training practices.
\end{abstract}

KEY WORDS: university social responsibility; university collaborators; Brazilian community universities; university administrative organization; institutional mission.

Recibido/Received: 05/05/2017

Aprobado/Aproved: 22/12/2017

Cómo referenciar este artículo / How to reference this article:

Antonio de Marco, R., Fanfa Sarmento, D., \& Pinto de Almeida, M. de L. (2018).

Responsabilidad social universitaria: la perspectiva de los colaboradores en una universidad

comunitaria brasileña. Tendencias Pedagógicas, 31, 289-308. doi:

http://dx.doi.org/10.15366/tp2018.31.016 


\section{INTRODUCCIÓN}

Las expectativas sociales alrededor de los resultados advenidos de las Universidades en relación con su papel social y contribución al desarrollo de la sociedad, requieren estructura institucional que permita observar la relevancia de sus objetivos de enseñanza, investigación y extensión. Según Nascimento (2014), dichas acciones deben ser desarrolladas de forma relevante internamente y fuera de ella, aportando reconocimiento por su alcance y contribución, además de demostrar eficacia formativa en la construcción de conocimientos esparcidos por sus egresados en la construcción de una sociedad más justa e igualitaria.

El autor asimismo subraya que cabe a las Instituciones de Enseñanza Superior (IES), particularmente las Universidades, la responsabilidad de conciliar la formación académica con objetivos económicos, sociales y ambientales. Así, debe incorporar en sus actividades de enseñanza, investigación y extensión, acciones propositivas e innovadoras que viabilicen el desarrollo de las habilidades y competencias técnicas de los futuros profesionales basadas en los principios éticos y valores morales, acercándose del ideario de la Responsabilidad Social en pro del Desarrollo Social.

Para Vallaeys (2006), la universidad tiene un papel central en sentido de orientar la formación general y especializada del estudiante, visando la promoción del desarrollo sostenible y su capacidad para construir una visión de mundo con base en la ética y en la capacidad de convivo democrático y participativo. Se espera, por tanto, que la comprensión de ese papel se exprese en las acciones de proveer el acceso al conocimiento de forma amplia, aportando a las personas la capacidad de comprender el mundo y buscar armonía en el convivo humano.

Se manifiesta en ese contexto la Responsabilidad Social Universitaria que, según Nascimento (2014), consiste en un comprometimiento universitario distinto con la formación de sus discentes en relación con la construcción de la ciudadanía, volviéndolos sensibles a los problemas sociales. Se trata, por tanto, de una construcción colectiva, que implica gestión, profesores y técnicos administrativos con ideario de compromiso social en sus actividades. Dichos elementos deben estar expresados en la concepción de misión de la universidad, poniendo a la IES en el compromiso social, estimulando los valores necesarios para la formación de ciudadanía por medio de acciones, nuevas prácticas, procesos, sistemas y actividades, implicando en el estímulo de una cultura propia que sostiene los preceptos de la Responsabilidad Social.

Los aspectos relacionados con la consecución de la Responsabilidad Social Universitaria ganaron relieve y valoración de parte de la comunidad académica desde la delimitación del instrumento de evaluación previsto por el Sistema Nacional de Avaliação da Educação Superior (SINAES) que estableció en su Eje 2: Desarrollo Institucional, desplegándose en las Dimensiones 1: Misión y Plan de Desarrollo Institucional y Dimensión; 3: Responsabilidad Social de la Institución, INEP (2004), que de forma definitiva señala la necesidad de adecuación de las IES al establecimiento de acciones y actividades que se vinculen a esa exigencia legal.

Se presenta a partir de esa constatación la problemática de que trata este texto, que es comprender cómo perciben los colaboradores - dirección, 
coordinadores, profesores y técnicos administrativos de las Universidades de carácter comunitario $^{6}$ - la implementación de acciones y actividades que demuestren con efectividad la Responsabilidad Social Universitaria.

Consonante al problema, el objetivo general de este texto es analizar cómo las IES de carácter comunitario perciben la implementación de la Responsabilidad Social en sus acciones, proyectos y preceptos institucionales. Específicamente, esa verificación ha pretendido ver en qué nivel de compromiso social se encuentran las actividades realizadas por la IES en la perspectiva de sus colaboradores directos, como dirigentes, coordinadores, profesores y técnicos administrativos.

Para atender a este ideario, fue realizada una investigación exploratoria y descriptiva, con carácter cuantitativo y cualitativo (Vergara, 2013; Gil, 2010). Fue aplicado un cuestionario que contempla ocho criterios para verificar si se hace efectiva la Responsabilidad Social Universitaria: inclusión social, desarrollo económico, desarrollo social, defensa del medio ambiente, defensa del patrimonio y memoria cultural, defensa de la producción artística y defensa de la producción deportiva y salud, y organización administrativa.

Este estudio presenta alta relevancia para las universidades comunitarias en especial, pues tendrán a su disposición un análisis criterioso sobre la percepción de los principales actores en el proceso de Desarrollo Social, ampliando la visión académica sobre sus prácticas universitarias resultantes de enseñanza, investigación y extensión. Así, el trabajo se organiza en seis secciones: la Introducción, que presenta la caracterización del estudio, la problemática, los objetivos propuestos y resultados esperados. En la segunda sección se presenta la fundamentación teórica que contempla la responsabilidad social universitaria y en el apartado tres se presentan los procedimientos metodológicos empleados en el estudio. El cuarto apartado se destina al análisis de los datos de la investigación aplicada y documental. En la quinta sección se delinean las consideraciones finales con las respectivas correlaciones teóricas $y$, por fin, el último apartado presenta las referencias bibliográficas utilizadas para el estudio.

\section{RESPONSABILIDAD SOCIAL UNIVERSITARIA (RSU)}

El tema Responsabilidad Social se halla emergente en el ámbito de las políticas educacionales. Sin embargo, hay poca claridad sobre el asunto, particularmente en la sociedad en general. En ese contexto, se destaca la ampliación del concepto y preocupación social de las acciones de la gestión de una Institución de Enseñanza, particularmente, de Enseñanza Superior, en lo que atañe al impacto social de las decisiones emanadas e irradiadas por las instituciones, sean ellas públicas o privadas.

El deseo de consolidar un sentido de responsabilidad social en la educación, especialmente en la enseñanza superior, se acerca a los preceptos iniciales sobre el tema. Según Alessio (2008) el marco de responsabilidad

\footnotetext{
${ }^{6}$ En Brasil hay universidades públicas, particulares y comunitarias. Entre las instituciones públicas están las federales, estaduales y municipales; las privadas, las hay con fines de lucro o mercantiles y las comunitarias y confesionales, que cumplen un importante papel social, están comprometidas con sus comunidades locales y regionales y no anhelan el lucro.
} 
social en las empresas ocurrió en los EEUU, en los años de 60 del siglo pasado, época en la que otros países todavía no tenían problemas de orden social. En esa perspectiva, Pernalete \& Ortega (2010) señalan que la responsabilidad social empresarial es el principal antecedente de la responsabilidad social comúnmente diseminada en los distintos tipos de organizaciones e instituciones.

La estructura evaluadora del Sistema contempla tres componentes: el de las IES (la autoevaluación, la evaluación externa), la evaluación de los cursos de grado (Organización Didáctico-Pedagógica, el Perfil del Claustro Docente y las Instalaciones físicas) y la de los estudiantes (la calificación en el Exame Nacional de Desempenho de Estudantes - ENADE). Asimismo, complementan el SINAES los siguientes instrumentos de información: Censo de la Educación Superior y Registro de Cursos e Instituciones (INEP, 2004). El conjunto de dimensiones evaluadoras del SINAES se organiza en cinco ejes y sus respectivas dimensiones de evaluación.

En el eje 2, Desarrollo Institucional, enfoque del estudio propuesto, son evaluadas las Dimensiones 1 y 3: Misión y Plan de Desarrollo Institucional (PDI) y la Responsabilidad Social de la Institución, respectivamente, contemplando los siguientes aspectos: misión institucional, metas y objetivos del PDI; coherencia entre el PDI y las actividades de enseñanza de grado y de posgrado; coherencia entre el PDI y las prácticas de extensión; coherencia entre el PDI y las actividades de investigación/iniciación científica, tecnológica, artística y cultural; coherencia entre el PDI y las acciones institucionales en lo que se refiere a la diversidad, al medio ambiente, a la memoria cultural, a la producción artística y al patrimonio cultural; coherencia entre el PDI y las acciones institucionales orientadas al desarrollo económico y social; coherencia entre el PDI y acciones de responsabilidad social: inclusión social; coherencia entre el PDI y acciones afirmativas de defensa y promoción de los derechos humanos e igualdad étnico-racial; internacionalización: coherencia entre el PDI y las acciones institucionales.

EI SINAES tuvo como propósito, desde su promulgación en 2004, abrir las puertas de oportunidades a la Responsabilidad Social en la gestión universitaria. De esa forma, la Responsabilidad Social constituye una exigencia a cualquier IES, sea pública o privada (Ashley, Ferreira, Reis, 2006). Así, para Vallaeys (2006, p. 39):

A Responsabilidade Social Universitária exige, a partir de uma visão holística, a articulação dos diversos setores da instituição, em um projeto de promoção social de princípios éticos e de desenvolvimento social equitativo e sustentável, com vistas à produção e transmissão de saberes responsável e à formação de profissionais cidadãos igualmente responsáveis ${ }^{7}$.

En esa perspectiva, Carrizo (2006) argumenta que las Universidades se deben transformar en instrumento del proceso de transformación social,

\footnotetext{
${ }^{7}$ En español: "La Responsabilidad Social Universitaria exige, a partir de una visión holística, la articulación de los distintos sectores de la institución, en un proyecto de promoción social de principios éticos y de desarrollo social equitativo y sustentable, con vistas a la producción y transmisión de saberes responsable y a la formación de profesionales ciudadanos igualmente responsables" (Traducción nuestra).
} 
atribuyéndoles la misión de dictar el ritmo de la historia, visión compartida por Florestan Fernandes (1975). Asimismo, Calderón (2006, p.8) señala:

Se por um lado, o entendimento da Responsabilidade Social Universitária que se tinha há mais de quatro décadas ainda mantém vigência, podemos afirmar que ele tem adquirido novos matizes em decorrência das rápidas mudanças ocorridas no mundo, em termos políticos, econômicos, culturais, informacionais decorrentes da crise do Estado de Bem-Estar, da hegemonia do neoliberalismo, da aceleração do processo de globalização econômica, do surgimento da sociedade global de informação e do conhecimento e, principalmente, do fim da guerra fria $^{8}$.

La RSU debe considerar los augurios de un mundo complejo, de diferencias sociales y desigualdades de oportunidades. Por estas argumentaciones, gana relieve la visión de Responsabilidad Social asociada directamente con el desarrollo humano, condición compartida por Wagenberg (2006), Kliksberg (2006), Vallaeys (2006), Carrizo (2006), y Morin (2002). Específicamente, Morin (2002) añade que el desarrollo en la perspectiva únicamente económica hace prevalecer la pobreza material y del alma en los socialmente excluidos, señalando la necesidad de diálogo permanente entre los procesos técnicos y económicos, aliados con preceptos éticos de solidaridad y responsabilidad.

En esta perspectiva, Santos (1995) subraya que los supuestos de la responsabilidad social deben atender a criterios hacia más allá de la perspectiva económica, estimulando el punto de vista de la orientación social y política ante problemas sociales. El autor señala que el reto consiste en poner en la misma línea la sustentabilidad institucional desde la perspectiva económica y los indicios de que la RSU valora el bienestar social y la vida humana como finalidad absoluta.

A su vez, Vallaeys (2006) defiende una nueva dinámica universitaria, que trasciende tres factores: la garantía de la responsabilidad social de la ciencia, la promoción de la formación ciudadana democrática y la formación cimentada en los fundamentos de la formación transversal de agentes para el desarrollo. Este sesgo formativo lo deben diseminar la enseñanza, la investigación y la extensión, elementos tradicionales y basales de las Universidades que, según Vallaeys (2006, p. 45), permiten la "construção das pontes entre a universidade e a sociedade, a concretização do compromisso social da universidade e a reflexão ética sobre a dimensão social do ensino e da pesquisa e têm sido uma atribuição da chamada extensão universitária"”.

Considerando esa perspectiva, Calderón (2006) y Vallaeys (2006)

\footnotetext{
${ }^{8}$ En español: "Si por una parte, el entendimiento de la Responsabilidad Social Universitaria que se tenía desde hace cuatro décadas todavía mantiene vigencia, podemos afirmar que él ha adquirido nuevos matices a causa de los rápidos cambios ocurridos en el mundo, en términos políticos, económicos, culturales, informacionales provenidos de la crisis del Estado de Bienestar, de la hegemonía del neoliberalismo, de la aceleración del proceso de globalización económica, del surgimiento de la sociedad global de información y del conocimiento y, principalmente, del fin de la guerra fría" (Traducción nuestra).

${ }^{9}$ En español: "construcción de puentes entre la universidad y la sociedad, la concretización del compromiso social de la universidad y la reflexión ética sobre la dimensión social de la enseñanza y de la investigación y ha sido una atribución de la denominada extensión universitaria" (Traducción nuestra).
} 
comparten la comprensión de que la RSU carece de una visión más bien abarcadora y sistémica, considerando las distintas partes de la institución en un proyecto de promoción social con principios éticos, sustentables, justos y de desarrollo social, sosteniendo al proceso de enseñanza y de aprendizaje para la transmisión de saberes con vistas a la formación de ciudadanos asimismo responsables socialmente. En esa perspectiva, La Jara (2006, p. 15) subraya que la RSU es la:

[...] capacidade que possui a universidade de difundir e colocar em prática um conjunto de princípios e valores, gerais e específicos, por meio de quatro processos considerados chaves: gestão, docência, pesquisa e extensão universitária, respondendo socialmente desta forma perante a própria comunidade universitária e o país onde está inserida $^{10}$.

Esa visión de La Jara (2006) está en armonía con las perspectivas anteriores - Calderón (2000, 2003, 2004, 2005, 2006); Wagenberg (2006), Kliksberg (2006), Vallaeys (2006); Carrizo (2006) - y añade un componente fundamental a la ejecución de la Responsabilidad Social: la gestión, contribución que se debe consolidar a partir de la definición de mecanismos administrativos que viabilicen la Responsabilidad Social en las Universidades. Se verifica, por tanto, que necesariamente pasa por la postura y modelo de Gobernanza de las Universidades, el deseo ejecutivo de orientar las actividades institucionales - Enseñanza, Investigación y Extensión aliadas a la postura de gestión, para atender al supuesto transversal de la Responsabilidad Social en las acciones y procesos de interacción con la sociedad.

La RSU, desde el punto de vista de la gestión, gana horizontes que, según Herrera (2009), incluyen un conjunto de acciones y procesos, cuyo objetivo es atender a las demandas de su ambiente de manera adecuada, formando un eslabón entre el conocimiento generado dentro de la Universidad y las necesidades locales, concibiendo una nueva postura de gestión bajo este prisma. Macedo (2004) pregona que la gestión asume una nueva dinámica que va más allá de la tradicional administración de patrimonio y de actividades académicas, suscitando un perfil democrático que fortalece la gestión social.

Calderón (2006) aclara que existe una estrecha relación entre las prácticas académicas Enseñanza, Investigación y Extensión, y las prácticas gerenciales - conjunto de procesos y estructuras gerenciales que permitan a las Universidades cumplir su misión institucional -, las cuales deberían estimular los principios y valores verificados en la base de la Responsabilidad Social Universitaria. Esos elementos, para Pernalete \& Ortega (2010) indican cómo la posibilidad de creación de una simbiosis entre universidad/sociedad, permitiría una relación que valorase todos los actores involucrados en ese proceso, desde la Universidad hasta la Sociedad.

Considerando este escenario, la comprensión de RSU bajo la mirada teórica permite refinar la reflexión sobre la Universidad en lo que atañe a su estructura funcional, orientación de las actividades académicas, y su forma de

\footnotetext{
${ }^{10}$ En español: "[...] capacidad que posee la universidad de difundir y poner en práctica un conjunto de principios y valores, generales y específicos, por medio de cuatro procesos considerados clave: gestión, docencia, investigación y extensión universitaria, respondiendo socialmente de esta forma ante la propia comunidad universitaria y el país donde está insertada" (Traducción nuestra).
} 
Gobernanza. Cabe subrayar que la preocupación con la Responsabilidad Social es un elemento presente en otras tipologías organizacionales, tales como las empresas. De acuerdo con Drucker (2009, p. 84):

Cada um é responsável pelo impacto que causa. [...] cedo ou tarde a sociedade vai considerar qualquer impacto causado um ataque à sua própria integridade e vai cobrar um alto preço daqueles que não tomaram para si a responsabilidade de trabalhar para eliminar 0 impacto ou para descobrir uma solução para o problema ${ }^{11}$.

El autor llama la atención para el hecho de que las organizaciones necesitan atentar y juntarse "às preocupações fundamentais da comunidade com os aspectos qualitativos da vida, isto é, bens e serviços econômicos, preocupação com a qualidade de vida, ou seja, com o ambiente físico, humano e social do homem moderno e da comunidade moderna ${ }^{12 "}$ (Idem).

Sin embargo, Vallaeys (2006, p.36) señala que la:

[...] Responsabilidade Social Empresarial é um conjunto de práticas da organização que integra sua estratégia corporativa e que tem como finalidade evitar danos e/ou gerar benefícios para todas as partes envolvidas na atividade da empresa (clientes, empregados, acionistas, comunidade, periferia etc.), com finalidades racionais, que devem redundar em benefício tanto da organização como da sociedade ${ }^{13}$.

Concerniente a los beneficios de la Responsabilidad Social Empresarial (RSE) hay que subrayar que ella es la contribución de las empresas para el desarrollo sostenible, en un trabajo que involucra a los empleados, a sus familias y a la sociedad en general, de modo que se mejore la calidad de vida tanto para las empresas, como para el desarrollo (Banco Mundial, 2002).

Ya Friedman (1970), caracteriza de forma pragmática a la RSE, como un concepto en el que las empresas, por medio de sus prácticas, colaboran voluntariamente para la mejora de la sociedad, valorando el desarrollo económico y la preservación del medio ambiente para la mejora de la calidad de vida de la sociedad. En ese sentido, Paoli (2002) señala que la RSE debe abarcar al cumplimiento de las normas laborales, el desarrollo económico con transparencia en sus cuentas, respeto al medioambiente e inversiones reales en mejora de la calidad de vida de la sociedad que interacciona con la organización.

En este contexto, la RSU carece de estrategias claras para su ejecución, según aborda Vallaeys (2006), sugiriendo cuatro líneas de acciones

\footnotetext{
${ }^{11}$ En español: "Cada uno es responsable del impacto que causa. [...] Tarde o temprano la sociedad va a considerar cualquier impacto como un ataque a su propia integridad y va a cobrar un alto precio de aquellos que no se encargaron de la responsabilidad de trabajar para eliminar el impacto o para descubrir una solución para el problema" (Traducción nuestra).

12 En español: "a las preocupaciones fundamentales de la comunidad con los aspectos cualitativos de la vida, es decir, bienes y servicios económicos, preocupación con la calidad de vida, mejor dicho, con el ambiente físico, humano y social del hombre moderno y de la comunidad moderna" (Traducción nuestra).

${ }^{13}$ En español: "[...] Responsabilidad Social Empresarial es un conjunto de prácticas de la organización que integra su estrategia corporativa y que tiene como finalidad evitar daños y/o generar beneficios para todas las partes involucradas en la actividad de la empresa (clientes, empleados, accionistas, comunidad, periferia etc.), con finalidades racionales, que deben redundar en beneficio, tanto para la organización, como para la sociedad" (Traducción nuestra).
} 
institucionales para su efectuación: 1) Gestión interna: transformar a la Universidad en una comunidad ética, socialmente ejemplar, democrática y transparente económicamente y políticamente, con énfasis en el desarrollo sostenible; 2) Docencia: orientar el aprendizaje basado en proyectos sociales, como enfoque multi e interdisciplinario, debido a su orientación en el aprendizaje articulado con la investigación, enseñanza y extensión; 3) Investigación: fomento a proyectos con fines de desarrollo social, utilizando estrategias integradas con la comunidad, preocupadas con la resolución de problemas locales; 4) Proyectos sociales: proceder una interfaz entre cursos, departamentos e investigadores y estudiantes, comprometidos en proyectos que se vuelvan fuente de investigación aplicada y de recursos didácticos para la comunidad universitaria.

\section{PROCEDIMIENTOS METODOLÓGICOS}

Para este ideario, fue realizada una investigación exploratoria y descriptiva, por tanto, de carácter cuantitativo y cualitativo (Vergara, 2013). La característica de la investigación, para Gil (2010), se presenta como una posibilidad segura de descripción de las características de determinada población, fenómeno o establecimiento de relación entre las variables.

Los datos se han colectado por medio de un cuestionario aplicado a 991 profesores, 22 dirigentes, 117 coordinadores y 732 técnicos administrativos utilizando el google docs. La investigación fue realizada entre los días 21 de marzo de 2017 a 10 de abril del mismo año.

El referido cuestionario fue adaptado de Nascimento (2014), considerando las características de las IES comunitarias en su compromiso con lo social, característica particular de su concepción y desarrollo. La obtención de los respectivos criterios tiene soporte en el artículo 3, Inciso III de la Ley n. 10.861/2004 que instituye el Sistema Nacional de Avaliação da Educação Superior - SINAES, y en los abordajes teóricos desarrollados por La Jara et al. (2006), Calderón (2006), Wagenberg (2006), Kliksberg (2006) y Vallaeys (2006). En ese sentido, están contemplados en ese abordaje los siguientes criterios y subcriterios:

1. Inclusión social: la infraestructura de accesibilidad en la universidad para docentes, discentes, técnicos administrativos y la comunidad en general con necesidades especiales; la ergonomía adecuada de los muebles y equipamientos para los portadores de necesidades especiales; Ia existencia de profesionales especializados en Língua Brasileira de Sinais (Libras) para la atención a los portadores de necesidades especiales; las acciones para integración de la universidad con el sector público, sector productivo y el mercado laboral; la ocupación de las plazas ofrecidas por la universidad por estudiantes de la región; acciones de comprometimiento con los valores éticos y morales.

2. Desarrollo económico: los proyectos de investigación en aparcería con el sector productivo; las innovaciones tecnológicas provenidas de las investigaciones ejecutadas; Ios impactos financieros en el municipio; El uso de metodologías para el estímulo al desarrollo de las habilidades emprendedoras. 
3. Desarrollo social: la ejecución de programas de inclusión social y acciones afirmativas; la política de incentivo a la educación continua para la comunidad universitaria y para egresados de los cursos.

4. Defensa del medioambiente: los proyectos pedagógicos de los cursos PPC con abordajes en la preservación del medioambiente; la política institucional de colecta selectiva de basura y los cuidados necesarios con el destino final de los residuos sólidos producidos por la institución; la existencia de proyectos de extensión para promover y diseminar las buenas prácticas de gestión ambiental.

5. Defensa del patrimonio y memoria cultural: la realización de cooperación técnica, eventos culturales y proyecto de extensión para valoración, rescate y mantenimiento del acervo histórico, de la cultura regional, del estímulo a la lectura y de la comprensión, la preservación del acervo histórico y del patrimonio cultural; los recursos presupuestarios para el mantenimiento de las acciones de defensa de la memoria cultural y patrimonial.

6. Defensa de la producción artística: política institucional de apoyo a la producción artística y cultural, realización de eventos y proyectos de extensión de estímulo al arte; disponibilidad de recursos presupuestarios para el mantenimiento de las acciones de las producciones artísticas.

7. Defensa de la producción deportiva y salud: la existencia de infraestructura para prácticas deportivas y ejercicios físicos de los docentes, discentes y técnicos administrativos; la existencia de profesionales especializados para la atención en las prácticas deportivas, en los ejercicios físicos y en el uso de los equipamientos; la disponibilidad de recursos presupuestarios para la realización de eventos deportivos, participación en torneos, campeonatos, como también la promoción a la salud.

8. Organización administrativa: Misión y Plan de Desarrollo Institucional.

Dichas dimensiones son ampliamente discutidas y difundidas como elementos esenciales para la verificación de la efectividad de la Responsabilidad Social Universitaria, permitiendo que el análisis correlacionado entre los criterios determine verificación más esmerada de esa temática para las Universidades comunitarias. Los datos han sido analizados desde la tabulación de los hallazgos de la investigación, utilizándose el Excel, generando gráficos y textos estimados por medio de la estadística descriptiva, recorriendo así el camino cuantitativo y cualitativo del análisis.

El campo de investigación fue una Universidad Comunitaria brasileña, institución reconocidamente de utilidad pública que trabaja en pro de la colectividad puesto que es entidad filantrópica. Permite conceder beneficios, como becas y modalidades de asistencia social, siendo considerada una institución de referencia en el estado de Santa Catarina, Brasil, em formar a personas, producir conocimiento y ofrecer extensión y servicios, promoviendo el desarrollo institucional y regional.

\section{ANÁLISIS Y DISCUSIÓN DE LOS RESULTADOS}

Los datos analizados se han originado en el universo de aproximadamente 991 profesores, 22 dirigentes, 117 coordinadores de curso y 732 técnicos administrativos. Al cuestionario contestaron el 6,1\% de los 
profesores, el $51 \%$ de los dirigentes, el $37 \%$ de los coordinadores de cursos y el $10,2 \%$ de los técnicos administrativos.

A continuación se presenta la percepción de los encuestados en relación con las siete dimensiones que comprende conjuntamente a los factores que dimensionan la efectividad de la Responsabilidad Social Universitaria en la IES comunitaria investigada: 1) inclusión social, 2) desarrollo económico, 3) desarrollo social, 4) defensa del medioambiente, 5) defensa del patrimonio y memoria cultural, 6) defensa de la producción artística, 7) defensa de la producción deportiva y salud, y 8) organización administrativa.

El gráfico 1 presenta el criterio 1) Inclusión Social, refiriendo a la inserción de personas con algún tipo de discapacidad en la educación superior.

\section{Gráfico 1: Inclusión Social}

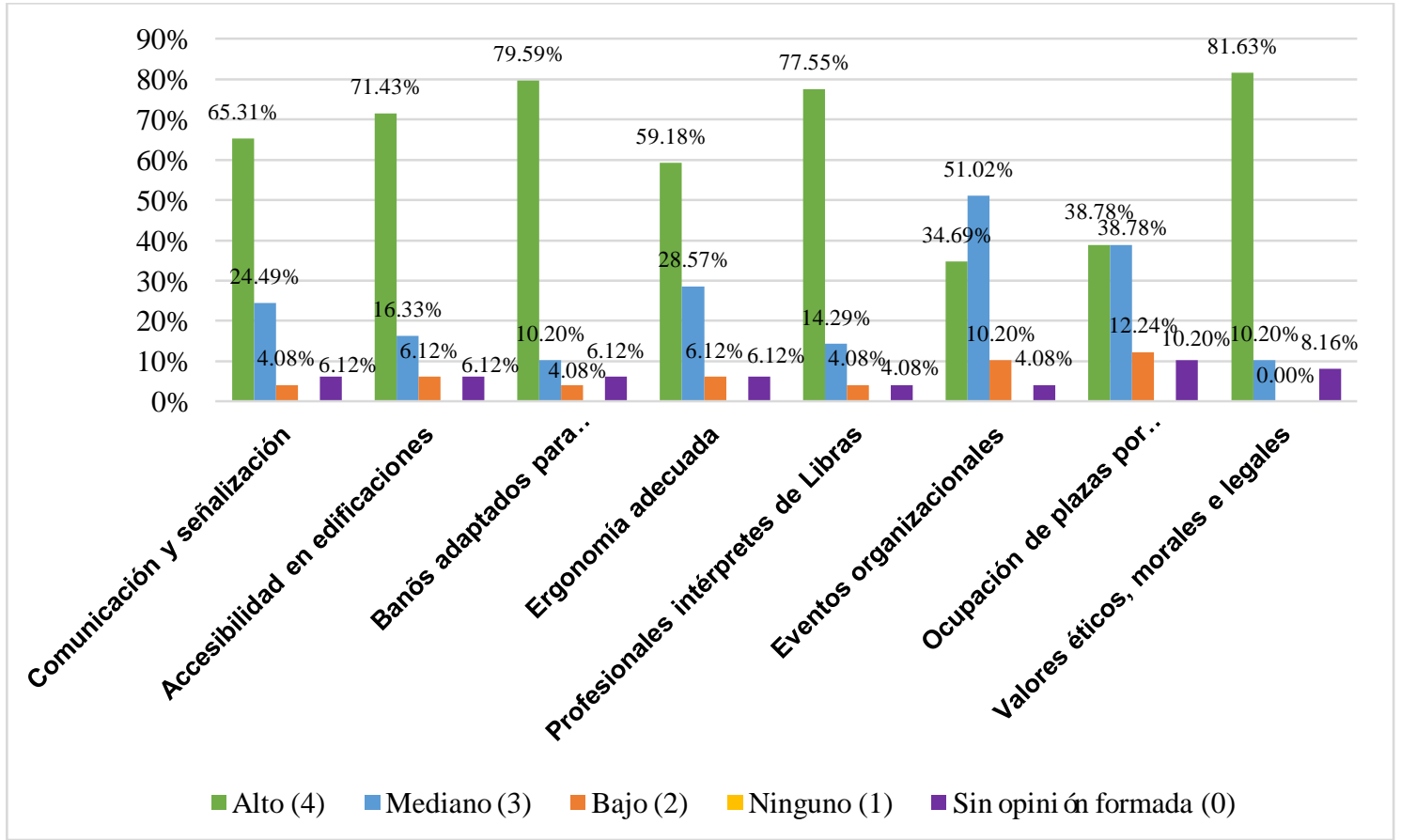

Fuente: Datos de la encuesta, 2017.

En la escala de 1 Ninguno, 2 Bajo, 3 Mediano, 4 Alto y Sin opinión, se ha extraído la siguiente conmensuración de los encuestados en relación con los subcriterios: fueron muy bien evaluados, con calificación cerca del máximo (4): comunicación y señalización; accesibilidad en edificaciones; baños accesibles para discapacitados; ergonomía adecuada; profesionales intérpretes de Libras y valores éticos, morales y legales. En relación con eventos organizacionales, la evaluación fue Mediana (3); sobre la ocupación de plazas por estudiantes de la microrregión, la evaluación resultó entre Mediano (3) y Alto (4). Además, se cuestionó sobre el peso de este criterio para el proceso de evaluación de la universidad en la dimensión de la Responsabilidad Social. 
Responsabilidad social universitaria: la perspectiva de los colaboradores en una universidad comunitaria brasileña

Gráfico 2: Criterio en el proceso de evaluación de la universidad

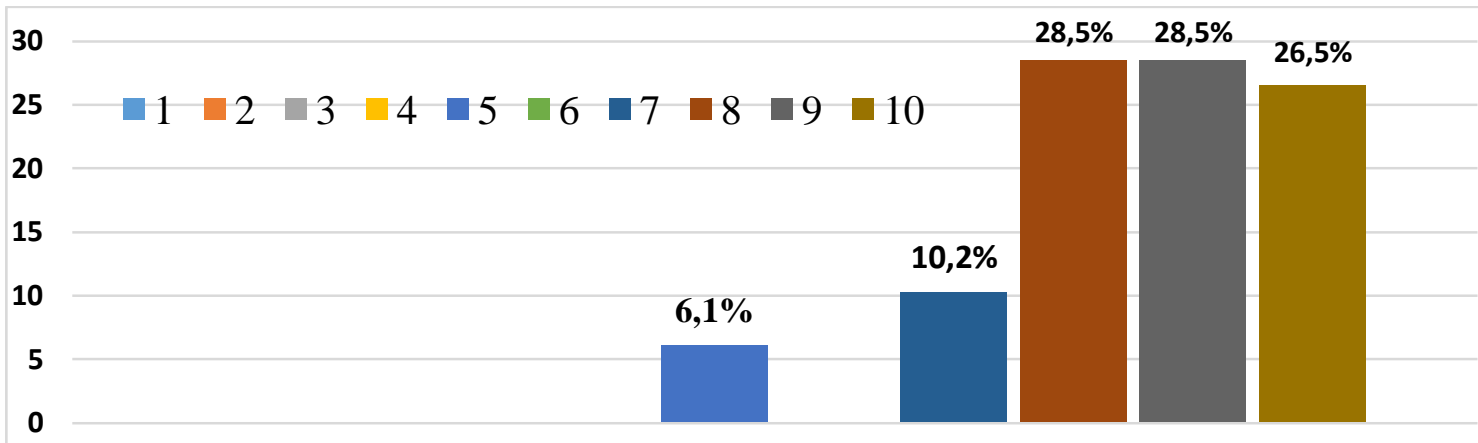

Elija un valor de 1 a 10

Fuente: Datos de la encuesta, 2017.

Se evidencia que hay una fuerte preocupación y percepción de la importancia de este criterio para la evaluación de la Universidad, puesto que la concentración de las respuestas está en su mayoría orbitando en la escala entre 8,9 y 10, donde están señaladas las calificaciones más altas de ese análisis.

El criterio 2) Desarrollo económico, se caracteriza por el desempeño macroeconómico, financiero y por los impactos en el consumo de recursos materiales y uso de energía. Está relacionado con los objetivos de eficiencia de los procesos productivos y con las alteraciones de consumo, orientado a una reproducción económica sostenible a largo plazo y será evaluado con los subcriterios a continuación.

Gráfico 3 - Desarrollo Económico

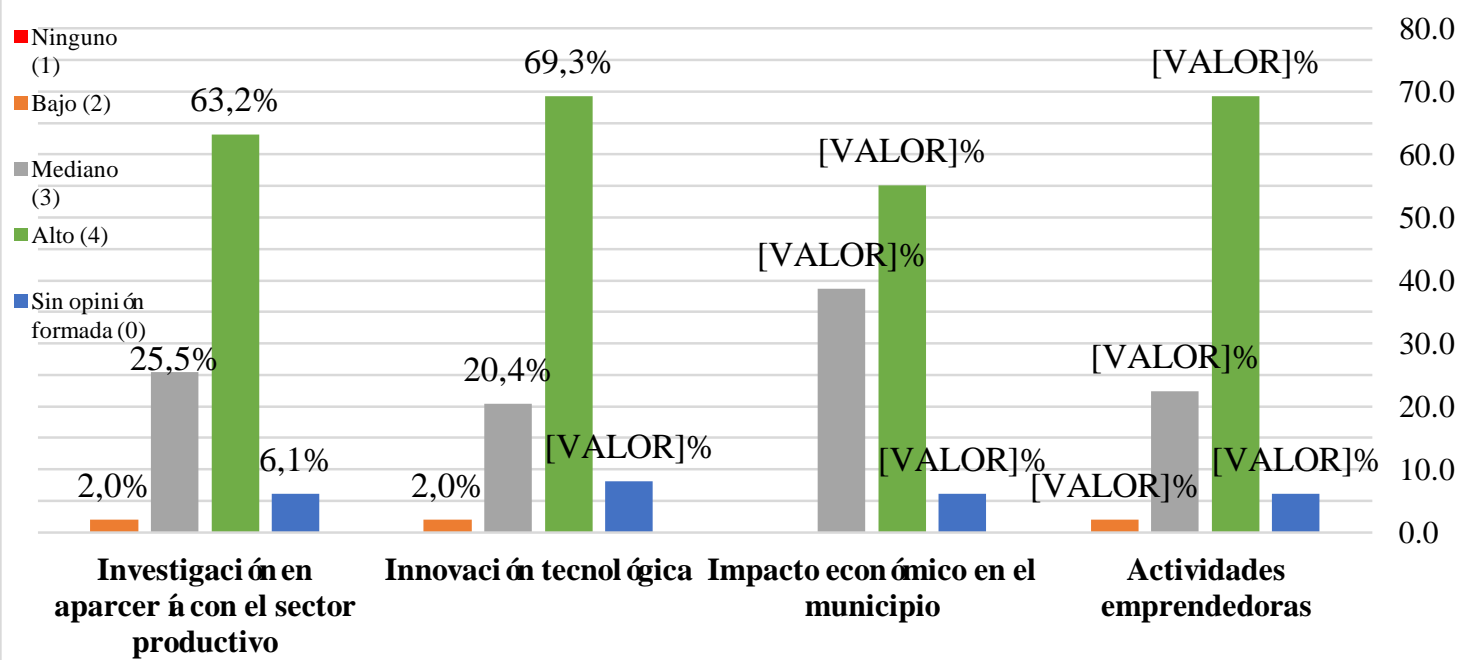

Fuente: Datos de la encuesta, 2017.

En ese aspecto, los datos demuestran la fuerte inclinación de la comunidad académica respondiente en reconocer con Alto (4) grado de importancia los subcriterios: investigación en aparcería con el sector productivo; innovación tecnológica; impacto económico en el municipio; y actividades emprendedoras. 
Además del criterio 2) Desarrollo Económico, se ha preguntado sobre el valor de este criterio para el proceso de evaluación de la universidad en la dimensión de la Responsabilidad Social, representado en el gráfico 4 a continuación.

Gráfico 4: Criterio desarrollo y el proceso de evaluación de la universidad

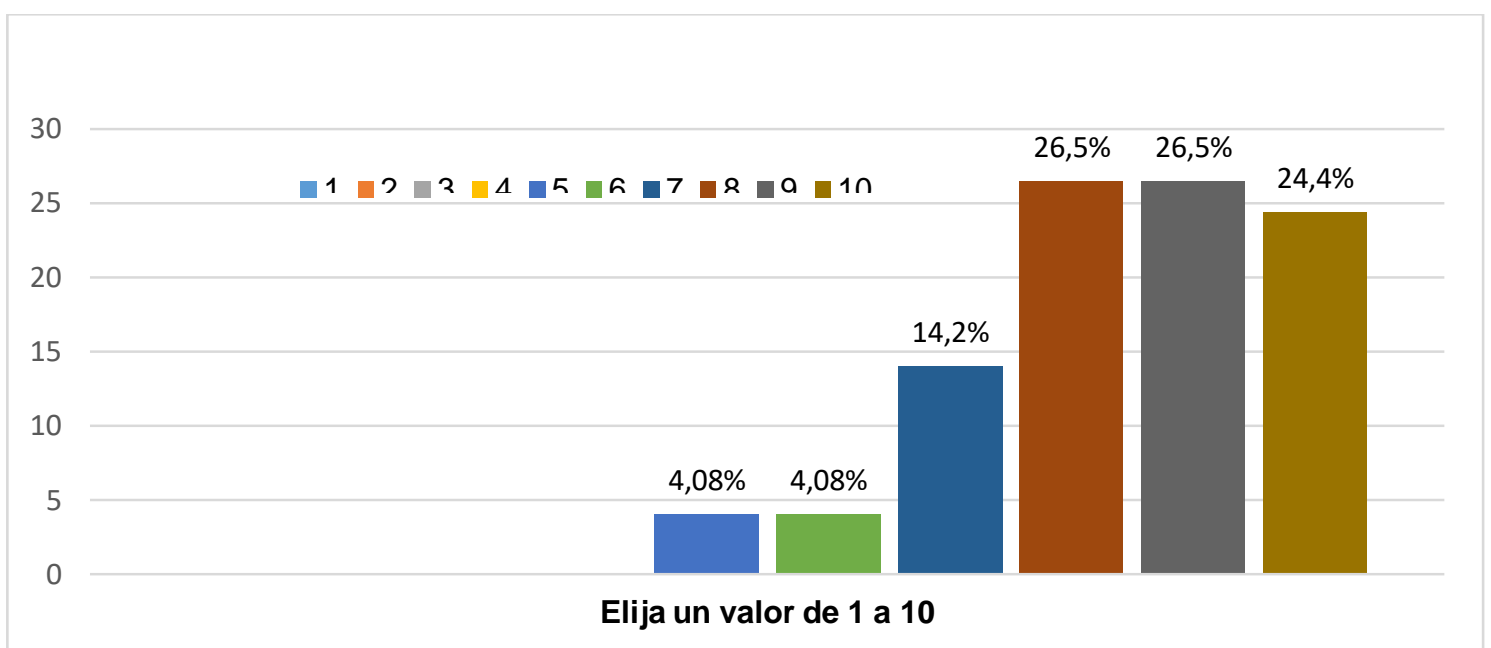

Fuente: Datos de la encuesta, 2017.

Se evidencia que hay una fuerte preocupación y percepción de la importancia de este criterio para la evaluación de la Universidad, puesto la mayoría de los encuestados se ubicó entre las escalas 8, 9 y 10, señalando los valores más altos de ese análisis.

El criterio 3) Desarrollo Social, atañe a la satisfacción de las necesidades humanas, mejora de la calidad de vida y justicia social en la perspectiva de la población sobre vivienda, trabajo y sueldo y será evaluado con los subcriterios a continuación.

Gráfico 5: Desarrollo Social

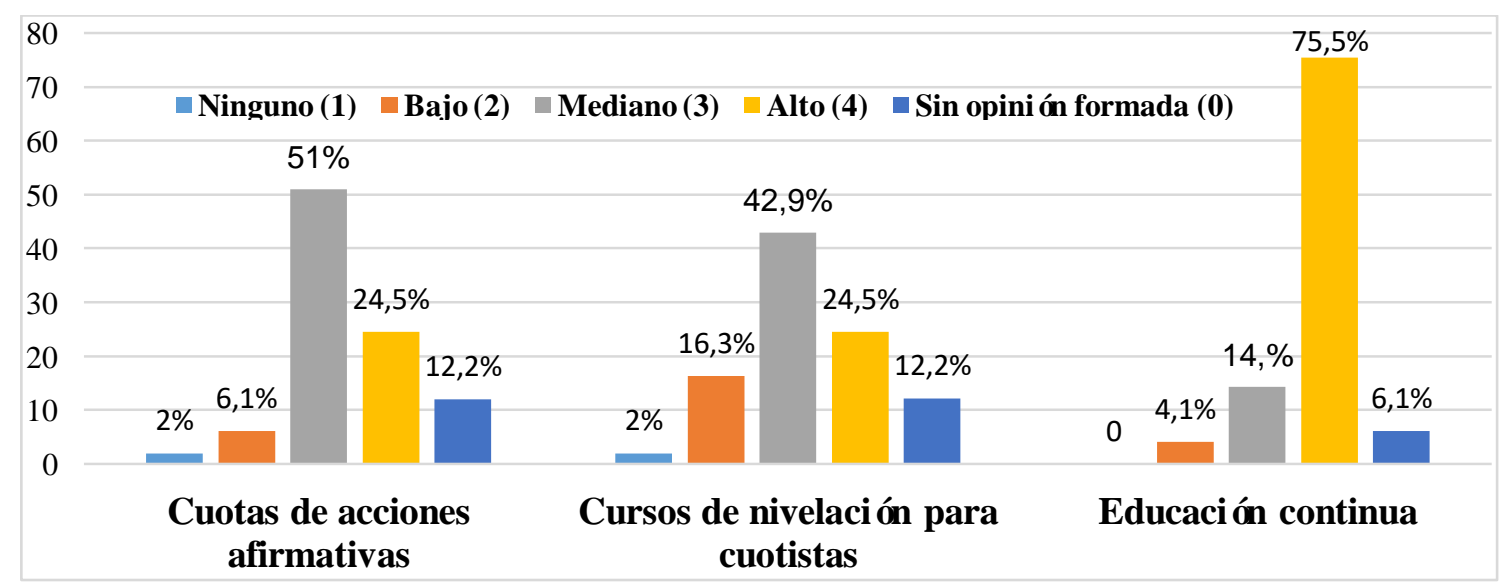

Fuente: Datos de la encuesta, 2017. 
En ese criterio los encuestados atribuyeron evaluación Mediana (3) a las cuotas de acciones afirmativas y cursos de nivelación para personas con limitaciones; y con Alta evaluación (4) la educación continua.

En la escala de 1 (uno) a 10 (diez) el peso del criterio desarrollo social para el proceso de evaluación de la universidad en la dimensión de la Responsabilidad Social, se ha observado concentración entre los ítems 7, 8, 9 y 10 , atribuyendo alta relevancia a este criterio.

Gráfico 6: Criterio desarrollo social en el proceso de evaluación de la universidad

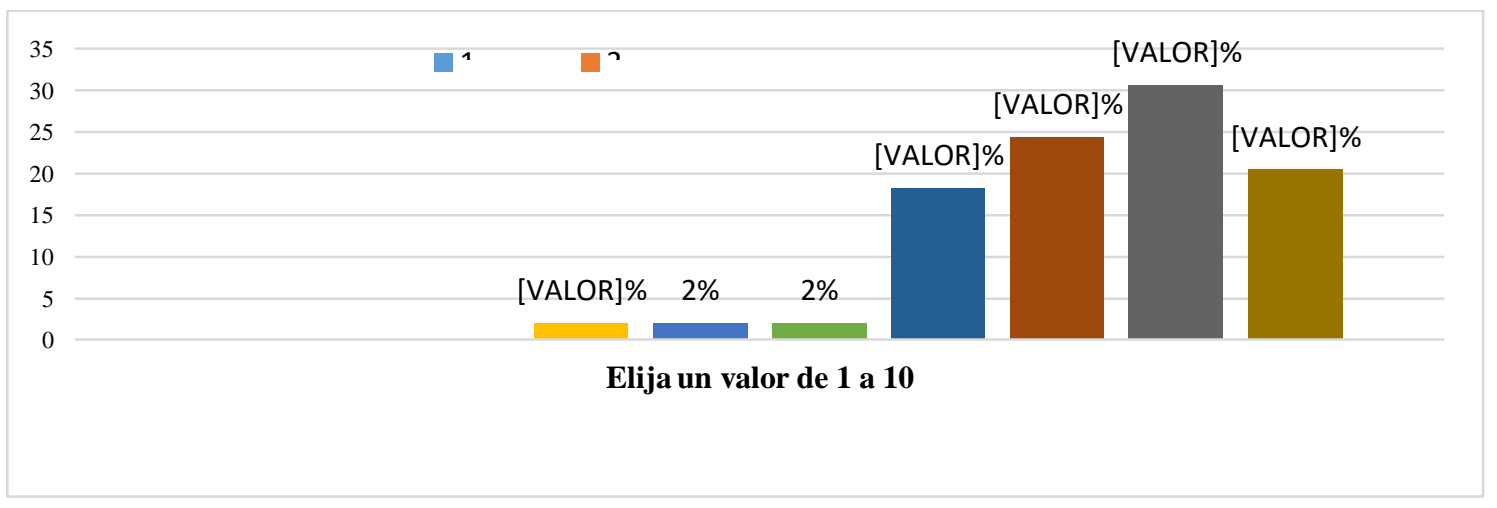

Fuente: Datos de la encuesta, 2017.

El criterio 4) Defensa del Medioambiente, relacionado con preservación y sustentabilidad del medioambiente urbano y rural; capacitación y calificación de los recursos humanos y de gestores de políticas públicas de medioambiente, presentó el siguiente comportamiento, explícito en el gráfico 7.

Gráfico 7: Defensa del Medioambiente

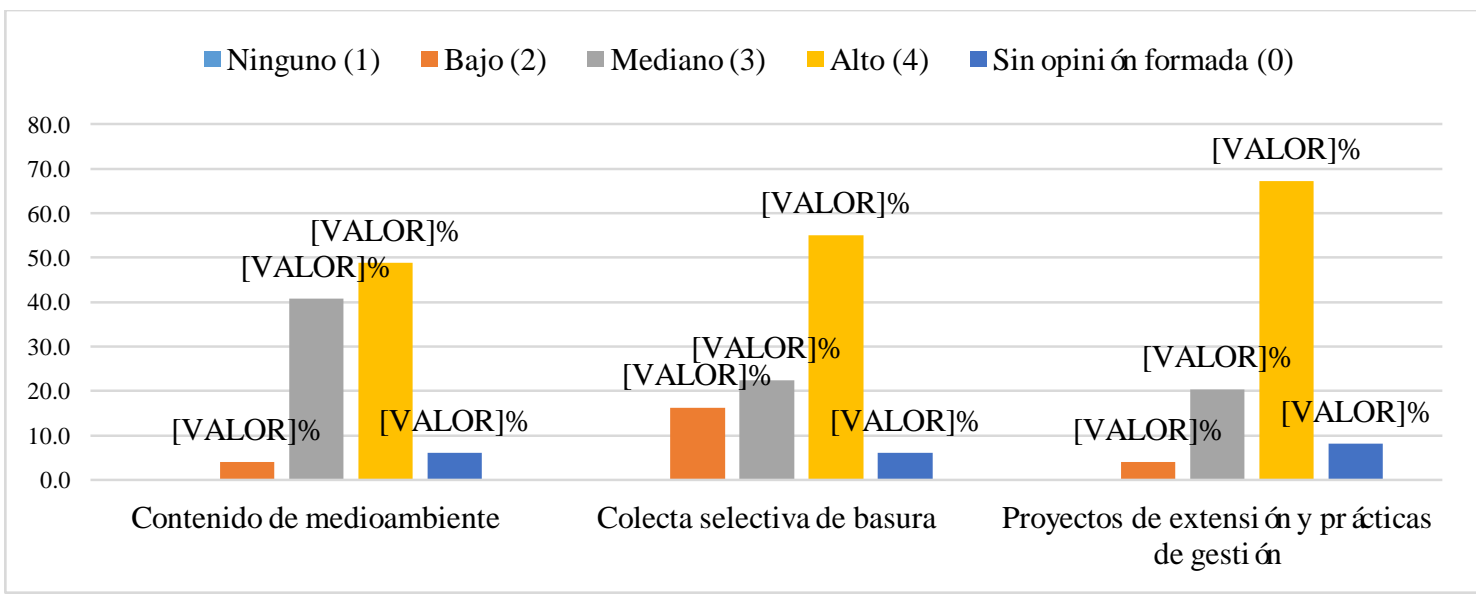

Fuente: Datos de la encuesta, 2017.

Con Alta intensidad (4) se ha identificado que las prácticas de colecta selectiva de basura y proyectos de extensión de prácticas de gestión tienen alta relevancia para el proceso de Responsabilidad Social Universitaria; el subcriterio contenido de medioambiente tuvo una percepción entre Mediano (3) y Alto (4). 
La percepción general de los respondientes también atribuye Alta relevancia a este criterio, hecho que concentró las respuestas entre 8,9 y 10 , demostrando que el criterio 4) defensa del medioambiente tiene alta importancia para el proceso de evaluación de la universidad en la dimensión de la Responsabilidad Social.

Gráfico 8: Criterio de defensa del medioambiente en el proceso de evaluación de la universidad

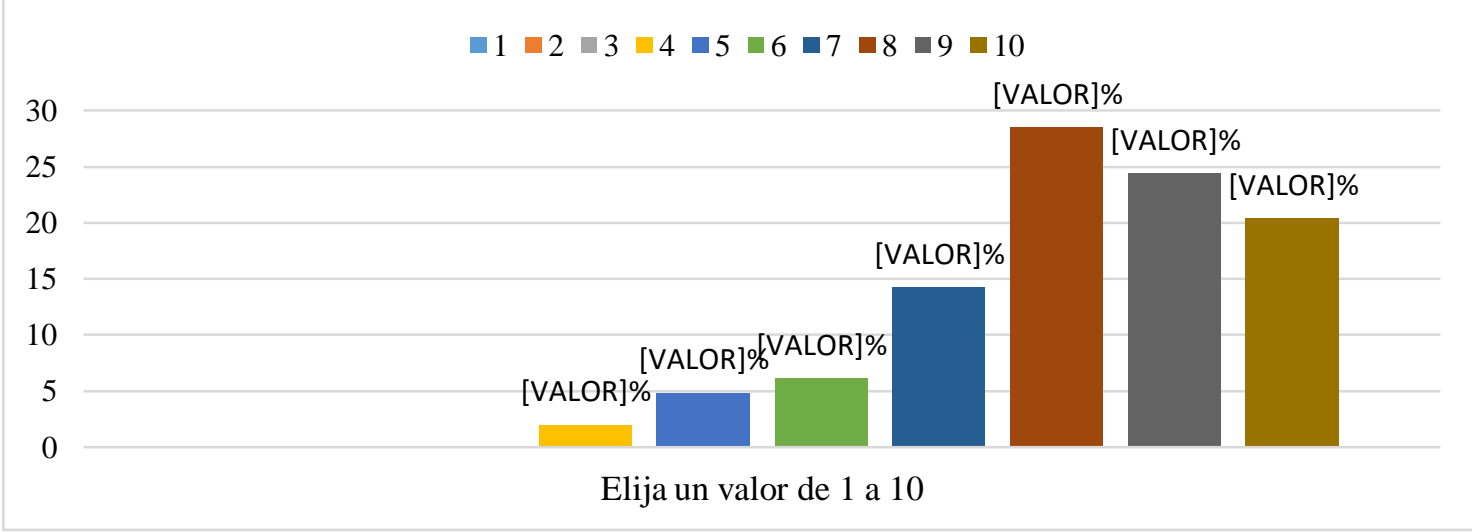

Fuente: Datos de la encuesta, 2017.

El criterio 5) Defensa del Patrimonio y Memoria Cultural contempla la preservación, recuperación y difusión de patrimonio artístico, cultural e histórico, mediante la formación, organización, mantenimiento, ampliación de equipamientos de museos, bibliotecas, centros culturales, colección y acervos; restauración de bienes muebles e inmuebles de reconocido valor cultural; protección al folclore, artesanía y tradiciones culturales.

Gráfico 9: Defensa del Patrimonio y Memoria Cultural

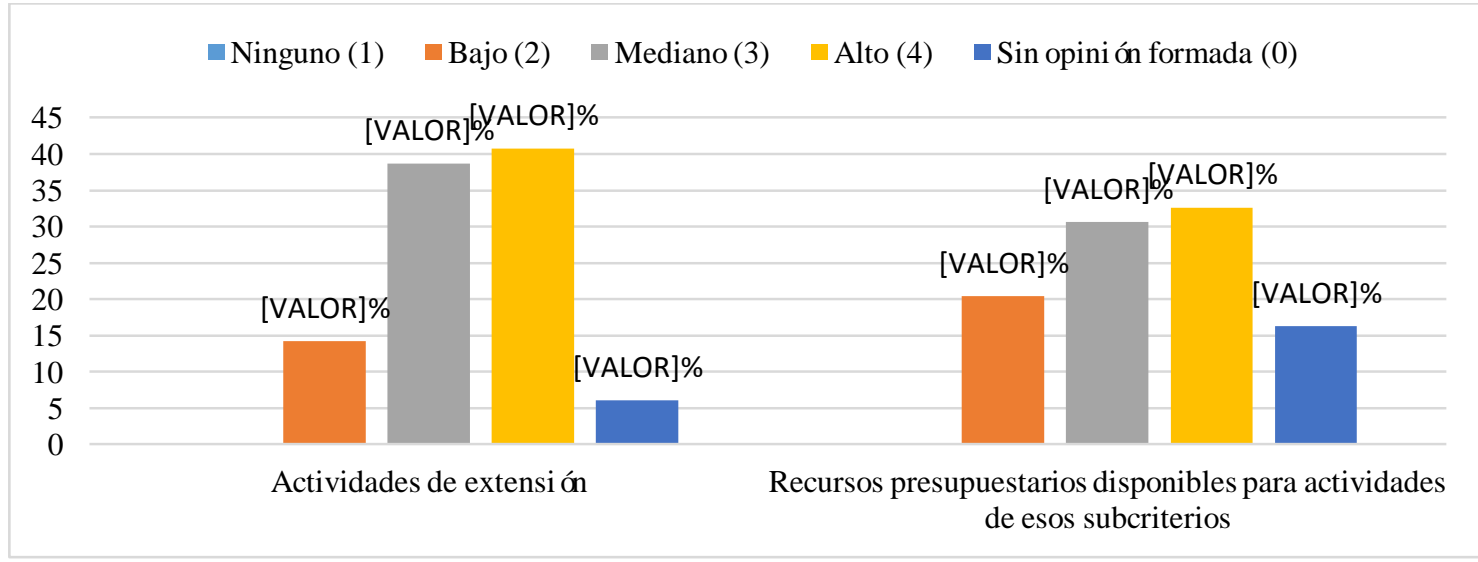

Fuente: Datos de la encuesta, 2017.

Las distribuciones de las respuestas para este criterio demuestran que actividades de extensión que promueven la defensa del patrimonio y memoria cultural tienen evaluación entre Mediano (3) y Alto (4); en relación con los recursos presupuestarios disponibles para actividades de este criterio se 
Responsabilidad social universitaria: la perspectiva de los colaboradores en una universidad comunitaria brasileña

obtuvo concentración de respuestas entre Bajo (2) y Mediano (3), superando Alto (4).

Sobre la importancia de ese criterio a la evaluación de la universidad en la dimensión de la Responsabilidad Social, hay concentración de las respuestas entre 7,8 y 9 , demostrando fuerza relativa para el proceso evaluativo.

Gráfico 10: Criterio defensa del patrimonio y memoria cultural en la evaluación de la universidad

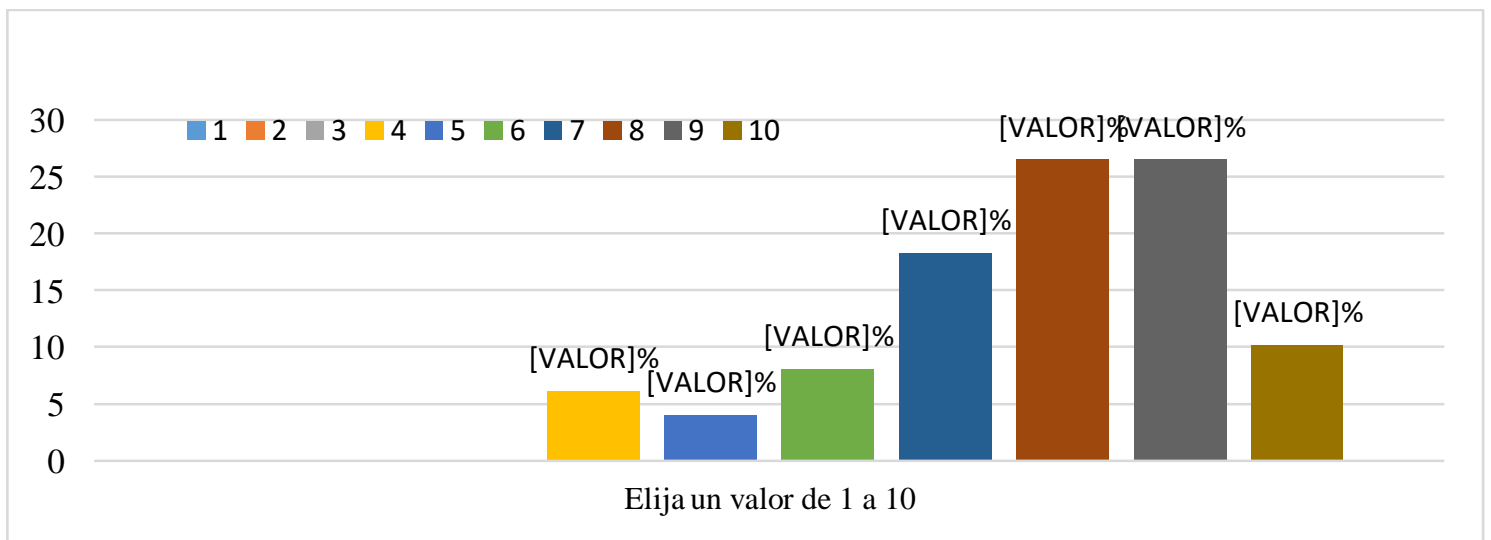

Fuente: Datos de la encuesta, 2017.

El criterio 6) Defensa de la Producción Artística se refiere a la producción y difusión cultural y artística de obras relacionadas con las ciencias humanas, letras y artes plásticas, fotografía, cine y vídeo. Se incluye, asimismo, teatro, música y danza, con el siguiente comportamiento entre los encuestados.

Gráfico 11: Defensa de la Producción Artística

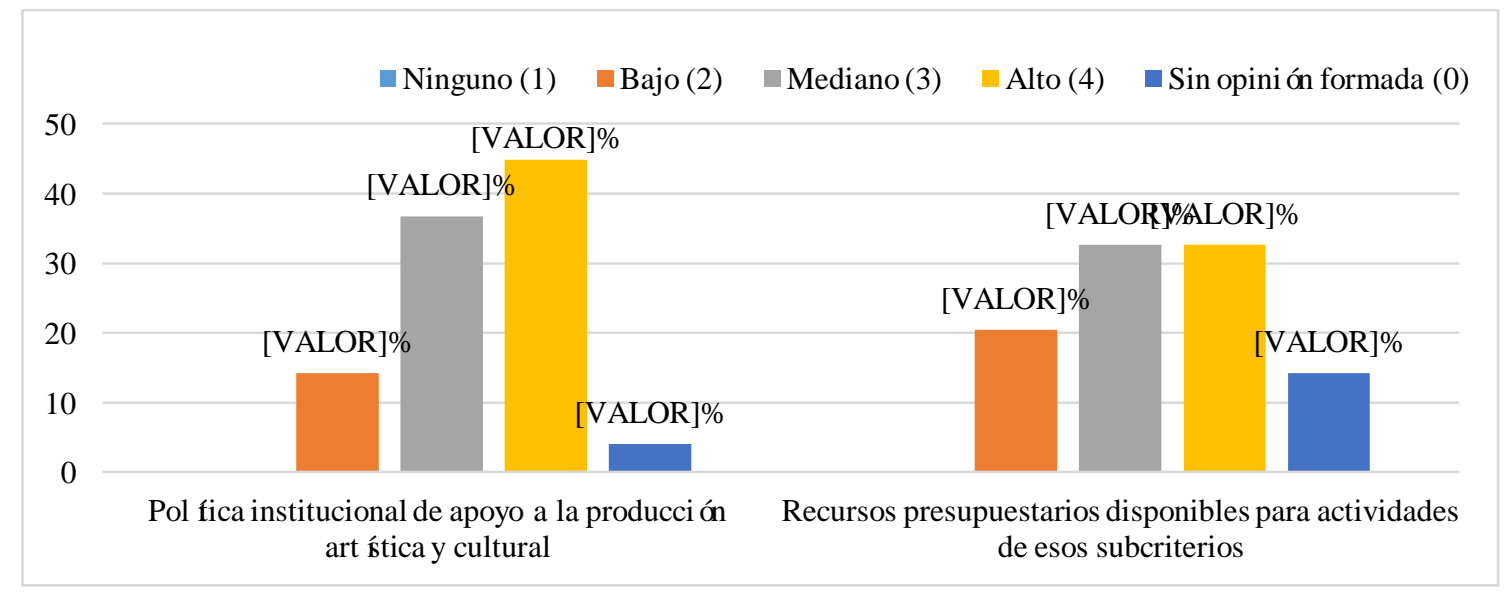

Fuente: Datos de la encuesta, 2017.

La política institucional de apoyo a la producción artística y cultural presenta evaluaciones Mediano (3) y Alto (4). Sin embargo, los recursos presupuestarios disponibles para actividades de esos subcriterios demuestran distribución entre Bajo (2), Mediano (3) y Alto (4). Este criterio no presenta un 
comportamiento lineal en relación con la importancia para el proceso de evaluación de la universidad en la dimensión de la Responsabilidad Social. Se evidencian respuestas con peso 5 y concentración en la calificación 7 , con distribución decreciente en 8, 9 y 10.

Gráfico 12: Criterio defensa de la producción artística para el proceso de evaluación de la universidad

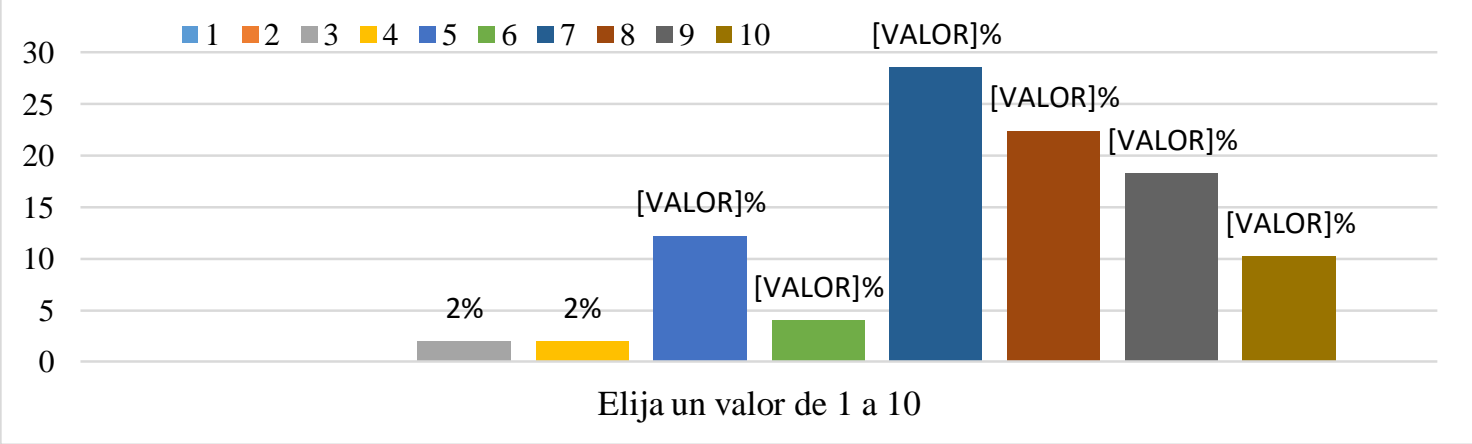

Fuente: Datos de la encuesta, 2017.

En relación con el criterio 7) Defensa de la Producción Deportiva y Salud, orientado al desarrollo de programas de salud, procesos asistenciales para dependientes de drogas, alcoholismo, tabaquismo, las repuestas demuestran el comportamiento según el gráfico 13.

Gráfico 13 - Defensa de la Producción Deportiva y Salud

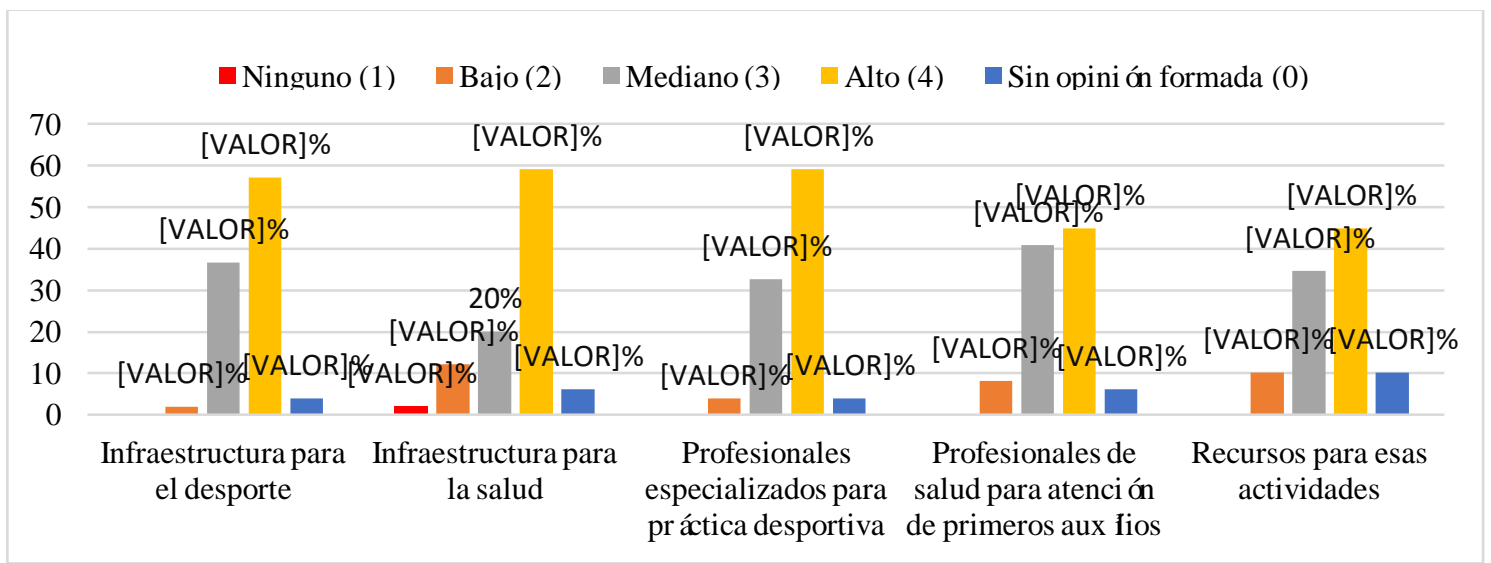

Fuente: Datos de la encuesta, 2017.

En ese aspecto, se percibe evaluación positiva a la infraestructura para prácticas deportivas y ejercicios físicos de los docentes, discentes y técnicos administrativos; la existencia de profesionales especializados para la atención en las prácticas deportivas, ejercicios físicos y utilización de los equipamientos; la disponibilidad de recursos presupuestarios para la realización de eventos deportivos, participación en torneos, campeonatos, como también la promoción a la salud como de alta prioridad, visto que la mayoría de las respuestas se concentra entre Mediano (3) y Alto (4). 
La percepción de los encuestados es que este criterio 7) defensa de la producción deportiva y salud tiene Alta relevancia al proceso de evaluación de la universidad en la dimensión de la Responsabilidad Social, visto que las respuestas se concentran en 8,9 y 10 .

Gráfico 14: Criterio defensa de la producción deportiva y salud en el proceso de evaluación de la universidad

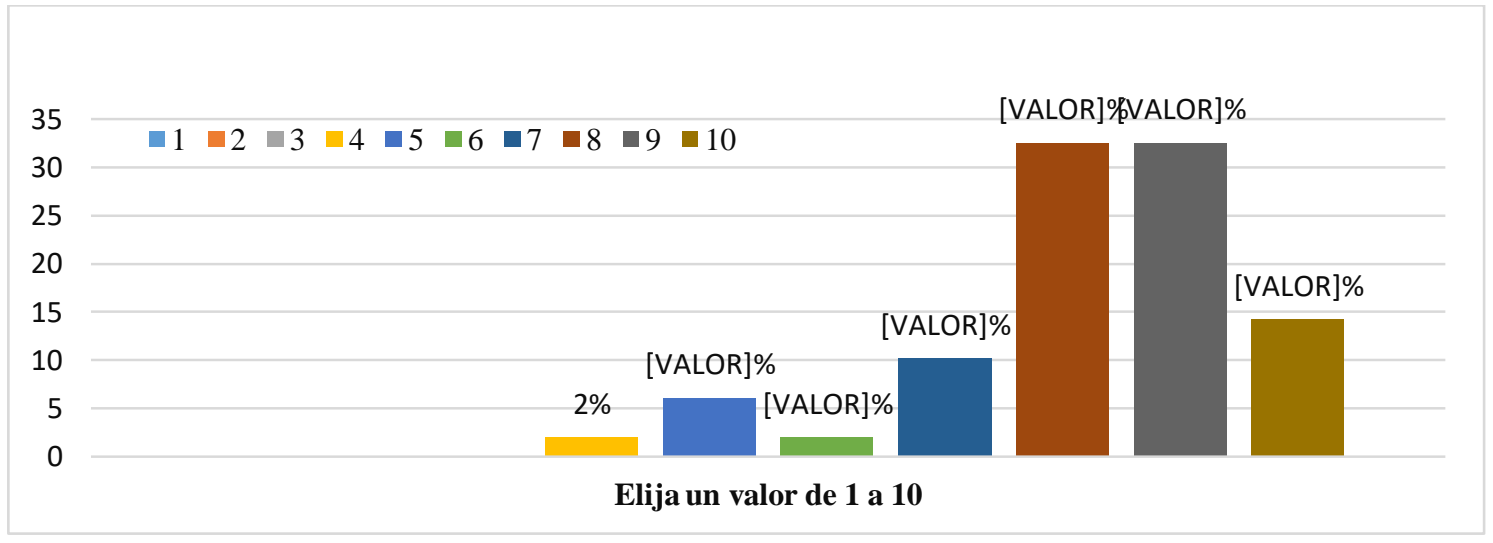

Fuente: Datos de la encuesta, 2017.

Sobre el criterio 8) Organización administrativa: Misión y Plan de Desarrollo Institucional, el análisis de los documentos oficiales de la institución demuestra que la misión expresa la finalidad mayor a que responde una institución universitaria. De esa manera, ella transciende la realidad contingente y transitoria, posee carácter de utopía, en sentido de que es posible pensar y proyectar la Institución en el presente y en el futuro. La misión para la cual la Universidad Comunitaria está constituida tiene que ver con su historia, con su identidad y con sus fines.

Considerada una de las mayores instituciones propulsoras del desarrollo, de la investigación, y de las perspectivas socioculturales y educacionales en las regiones de alcance, la Universidad Comunitaria prevé en su visión ser una universidad reconocida por la excelencia académica y tener actuación como agente de desarrollo regional. El desarrollo de la Institución trasciende las construcciones que han edificado a lo largo de los años, él se manifiesta, igualmente, en la transformación de la cultura, del conocimiento, de las condiciones de formación de las personas que han tenido acceso a la enseñanza superior y de las condiciones de mejora de la calidad de vida personal y profesional de las personas. La visión expresa las expectativas, los deseos de la comunidad académica y de la sociedad en relación con un futuro deseable y posible para la institución. Para ello, ella necesita ser abarcadora, desafiadora, inspiradora e innovadora.

Valores son principios de conducta construidos y seguidos por los colaboradores de la institución, dando identidad y credibilidad a la institución. Deben ser significativos, compartidos y duraderos, por tanto, la Universidad Comunitaria abordada en esta investigación nació y creció anclada a valores basados en la ética, en el humanismo, en la cooperación, en el comprometimiento, en la responsabilidad social, en la innovación y en la 
solidez. La identidad comunitaria se refleja en sus acciones desarrolladas en las áreas de la educación, salud, asistencia social, tecnológica, ambiental, cultural y de ocio, con objetivo de difundir el conocimiento y llevar calidad de vida a las personas, preservando sus valores.

\section{CONSIDERACIONES FINALES}

Los resultados de esa investigación, que tomó en cuenta ocho criterios para evaluar la efectividad de la Responsabilidad Social Universitaria en una Universidad Comunitaria - Inclusión social; Desarrollo económico; Desarrollo social; Defensa del medioambiente; Defensa del patrimonio y memoria cultural; Defensa de la producción artística; Defensa de la producción deportiva y salud y Organización administrativa -, demuestra la preocupación de la IES investigada con el Desarrollo Social, particularmente, la implementación de los preceptos que sostienen la Responsabilidad Social Universitaria, visto que no se han verificado desvíos significativos de respuestas en la atribución de importancia y de relevancia para cada criterio analizado.

Consolida, por tanto, la visión de que la Responsabilidad Social Universitaria debe pasar por organización administrativa adecuada, debidamente orientada, en que atribuye la misión institucional y sus documentos oficiales constitutivos, en este caso, el Plan de Desarrollo Institucional, la previsión del Desarrollo Social, reconocidamente como aliado y guía de las acciones, proyectos y actividades que consolidan las prácticas de formación ciudadana. Concomitante, resultó evidente que el Desarrollo económico se pone como criterio preponderante para que se concretice la Responsabilidad Social Universitaria, visto que, desde su consolidación, se reúnen condiciones de estimular la inclusión social, la defensa del medioambiente, del patrimonio y memoria cultural, defensa de la producción artística y de la producción deportiva y salud.

En esa perspectiva, se percibe que la emergencia social de soluciones a problemas de las personas induce a que las IES comunitarias asuman su responsabilidad en ese proceso, influenciando su práctica de gestión, comprometiéndose, por medio de su visión, misión y documentos institucionales como el PDI, con los reflejos perversos de una sociedad de grandes desigualdades, siendo capaz de soportar, en alguna medida, los excluidos por la pobreza, por el hambre, la falta de seguridad, las enfermedades y por la falta de garantías de sus derechos sociales. Para ello, se presenta necesaria la incorporación de preceptos éticos y de ciudadanía ajustados a la realidad social, sosteniendo la enseñanza, la investigación y la extensión universitaria, enraizando culturalmente esas praxis (Calderón, 2006; Kliksberg, 2006; Vallaeys, 2006).

A partir de este ideario, fue posible percibir que la IES investigada, en sus principios constitutivos y documentos oficiales, fomenta la calidad de la enseñanza por medio de la valoración de la formación ciudadana orientada a la inserción social. Se ha constado que la consolidación de la RSU en IES comunitarias pasa necesariamente por la mirada atenta de la gestión a sus preceptos constitutivos. Asimismo, al principio de la insociabilidad entre la enseñanza, investigación y extensión, elementos constitutivos y fines de las universidades, que cuando no ejecutados adecuadamente, contrarían e hieren 
el precepto legal; que proyectos de Enseñanza, Investigación y Extensión, de cuño inter y transdisciplinario, presentan fuerte contribución a la consolidación de la calidad de la Enseñanza y de la RSU.

Así, se cumple el objetivo general de este trabajo, en el que se ha verificado el alto grado de comprometimiento de esa Universidad Comunitaria con la causa social, con su desarrollo, con su inserción en prácticas, proyectos, acciones, actividades y en el enlace entre enseñanza, investigación y extensión, además de la preocupación de su dirección con la formación ciudadana.

Resultó evidente asimismo la armonía entre la organización administrativa y la vida institucional; formación docente y académica; investigación y producción de conocimiento; proyección social y voluntariado; acercándose al ideario de consolidación de la RSU para las IES comunitarias, considerando como elementales los criterios de inclusión social, defensa del medioambiente, del patrimonio y memoria cultural, defensa de la producción artística y producción deportiva y salud.

\section{REFERENCIAS BIBLIOGRÁFICAS}

Alessio, R. (2008). Responsabilidade Social das Empresas no Brasil: reprodução de postura ou novos rumos. Porto Alegre, EDIPUCRS.

Ashley, P. A., Ferreira, R. \& Reis, H. L. (2006). Sistema Nacional de Avaliação da Educação Superior: Oportunidades para a responsabilidade social na gestão estratégica de instituições de ensino superior. Revistas Gerenciais, São Paulo, v. 5, p. 23-35.

Banco Mundial. (2002). Public sector roles in strengthening corporate social responsibility: a baselinestudy. Washington.

Calderón, A. I. (2000). Universidades mercantis: a institucionalização do mercado universitário em questão. São Paulo em Perspectiva, São Paulo, v. 14, n. 1. https://doi.org/10.1590/S0102-88392000000100007

Calderón, A. I. (2003). A Universidade mercantil e o caso da universidade pública: reflexões a partir da experiência chilena. Eccos Revista Científica, São Paulo, v. 5, n. 1. https://doi.org/10.5585/eccos.v5i1.337

Calderón, A. I. (2004). Repensando o papel da universidade. RAE-Revista de Administração de Empresas, São Paulo, v. 44, n. 2, abr./jun. https://doi.org/10.1590/S0034-75902004000200009

Calderón, A. I. (2005). Responsabilidade social: desafios à gestão universitária. Estudos, Brasília, DF, ano 23, n. 34, p. 13-39, abr.

Calderón, A. I. (2006). Responsabilidade social universitária: contribuições para o fortalecimento do debate no Brasil. Revista da Associação Brasileira de Mantenedoras de Ensino Superior. Associação Brasileira de Mantenedora de Ensino superior. - Brasília, Ano 24, n. 36 (Jun. 2006).

Carrizo, L. (2006). Conhecimento e responsabilidade social: ameaças e desafios para a universidade transdisciplinar. Estudos, Brasília-DF, ano 24, n. 36, p. 76-89, mar. 2006. 
Drucker, P. F. (2009). O melhor de Peter Drucker: A administração. São Paulo: Nobel.

Fernandes, F. (1975). Universidade brasileira: reforma ou revolução. São Paulo: Alfa-Omega.

Friedman, M. (1970). The social responsibility of business is to increase its profits. New York Times Magazine, september.

Gil, C. A. (2010). Como elaborar projetos de pesquisa. São Paulo: Atlas.

Herrera, A. (2009). Responsabilidade social das universidades. In: GUNI. Educação superior em tempos de transformação: novas dinâmicas para a responsabilidade social. Porto Alegre: EDIPUCRS, p. 41-42.

INEP. (2004). Lei no 10.861, de 14 de abril de 2004. Institui o Sistema Nacional de Avaliação da Educação Superior - SINAES e dá outras providências. Diário Oficial da União, Brasília-DF, 15 abr. 2004.

Kliksberg, B. (2006). A ética e a responsabilidade social da universidade. Estudos. Revista da Associação Brasileira de Mantenedores de Ensino Superior. Brasília-DF, Ano 24, n. 36, mar. p. 23-25.

La Jara, M. J. et al. (2006) Responsabilidade universitária: uma experiência inovadora na América Latina. Estudos, Brasília-DF, ano 24, n. 36, p. 5773.

Macedo, A. R. (2004). O papel social da universidade. Estudos. Brasília-DF, Ano 23, n. 34, abril, p. 7-12.

Morin, E. (2002). ¿Estamos en un Titanic? In: KLIKSBERG, Bernardo. Ética y desarrollo: la relación marginada. Buenos Aires: El Ateneo, 2002, p. 143148.

Nascimento, J. M. L. (2014) Índice de Responsabilidade Social da Universidade: uma Metodologia de Avaliação Institucional. 217 páginas. Tese (Programa de Pós-graduação em Recursos Naturais), Universidade Federal de Campina Grande, Campina Grande/PB.

Paoli, M. C. (2002). Empresas e responsabilidade social: os enredamentos da cidadania no Brasil. In: SANTOS, B. S. (Org.) Democratizar a democracia: os caminhos da democracia participativa. Rio de Janeiro: Civilização Brasileira.

Pernalete, M. T. \& Ortega, M. T. (2010). Responsabilidad Social de la Universidad: retos y perspectivas. Buenos Aires: Paidós.

Santos, B. de S. (1995). Pela mão de Alice: o social e o político na pósmodernidade. São Paulo: Cortez Editora.

Vallaeys, F. (2006). Que significa responsabilidade social universitária? Estudos. Brasília-DF, ano 24. oㅜ 36. Junho, pp.35-56.

Vergara, S. C. (2013). Projetos e relatórios de pesquisa em administração. São Paulo: Atlas.

Wagenberg, A. (2006). A urgência da responsabilidade social universitária. Estudos, Brasília, DF, ano 24, n. 36, p. 27-34. mar. 